\title{
Portraying Privacy Leakage of Public WiFi Systems for Users on Travel Spam Detection in Social Bookmarking System
}

\author{
C.Geetha, Vimala. D, S.Amudha
}

\begin{abstract}
In this paper, we depicts spam revelation, in perspective of the examination of posts, in social bookmarking districts. For consistent acknowledgment of spam posts, we propose a name estimation plot and a specific evaluation procedure for picking marks. The label estimation scores each tag. In the particular evaluation, the label scores in perspective of the utilization repeat and the degree of spammers are estimated and the thoughts of white tag and dim tag are introduced. Using these thoughts, names are proficiently arranged into the names demolishing the execution of spam revelation, the names pleasing in getting spammers, and the marks which should achieve a discipline. Finally, we propose semantic components to moreover upgrade the spam distinguishing proof.
\end{abstract}

Keywords: spam discovery; social spam; label measurement

\section{INTRODUCTION}

Casual association Services (SNSs, for instance, Flickr, Twitter, and Tasty have been getting commonness of late. As the quantity of customers of SNSs has extended, the amount of spammers striking such districts has also grown rapidly. We propose a spammer disclosure methodology in social bookmarking areas[1],[3],[5]. Social bookmarking systems are chosen for examination since the posts in the structures are made out of segments that are by and large used as a piece of most SNS districts, e.g., marks, URLs, subjects, depictions, et cetera. Subsequently, the proposed spam disclosure methodology is material to a broad assortment of SNS regions. For persistent area of spammers, the proposed method grasps post-level examination that investigates the marks of each post to perform spam portrayal[2],[4],[6]. The name assessment (scoring) scheme is proposed to create scores for marks, and names are arranged by the thoughts of white names and dim names in perspective of their scores. In the specific appraisal arrange, the marks that are valuable in getting spammers and those that should be dismissed in spam area (i.e., the names not obliging in isolating spammers from genuine customers) are picked autonomously to extend the viability of spam revelation.

They would now have the capacity to post reviews of a thing at dealer areas and express their points of view and

\section{Revised Manuscript Received on July 22, 2019.}

C.Geetha, Department of Computer Science and Engineering, Bharath Institute of Higher Education and Research, Chennai , India. Email kavithag90@gmail.com

Vimala D, Department of Computer Science and Engineering, Bharath Institute of Higher Education and Research, Chennai , India. Email pstopvc@bharathuniv.ac.in

S.Amudha, Department of Computer Science and Engineering, Bharath Institute of Higher Education and Research, Chennai , India. Email: mssadagopan@gmail.com speak with others through online diaries and dialogs[7],[9],[11]. Such usergenerated content on the web gives pivotal information on these things which help potential customers to find suppositions of existing customers beforehand purchasing a thing. Constructive supposition makes one buy the thing, and the pessimistic evaluation will settle on one change his acquiring decision, thusly constructive suppositions result into colossal thing bargains, money related benefits and reputations for affiliations and individuals as well. Such hugeness of reviews could be broke down for various vindictive applications[8],[10],[12].

The growing sending of open remote access concentrates (generally called hotspots) and the inescapability of advantageous figuring devices, for instance, tablets and mobile phones have made it more supportive for people to get to information on the Internet. Nowadays, agents, visit voyagers what's more, people amidst a leave of absence can without quite a bit of an extend access to a framework from any open remote access centers.

In this paper, we take a gander at the potential assurance spillage out in the open hotspots from the customer end works out, for instance, web examining, web crawler addressing and mobile phone applications utilize. We gather and eviscerate packs of clients from fifteen specific air terminals at various time and make more than twenty datasets. We perceive essential structure parameters that can be utilized to profile client's private data from open system improvement and delineate client security spillage in context of their monstrosity for various protection classes.

A thinking motor is proposed to trigger undeniable confirmation assurance portions to tailor relating security necessities. Understanding the security spillage of the hotspot systems has both explicit effect and social effect. To the degree specific effect, it can bolster better security insistence systems. For instance, program modelers can offer a changed security assurance interface to fulfill extraordinary security prerequisites; site masters can encode touchy data, for example, success records and cash related data; working framework designers can give clients an altered security plot in context of clients' contrasting protection concerns[13],[15],[17].

\section{RELATED WORKS}

Assurance spillage in regular online casual groups has been extensively thought, for instance, [6]. These written work generally focus on the insurance issues in casual groups in perspective of the customer dispersed data, for instance, 


\section{An Exploration of Fiber-Optic Cables}

recognizing customer relationship besides, depicting customer outlines.

After the ordinariness of substance movement frameworks and advancement frameworks, reidentification in pariah aggregators transforms into another security concern. To overcome this issue, diverse security control instrument for pariah aggregators are considered [4] [6].

Novel in association with past security examination, our work does not depend upon social affiliation stages to perceive client confirmation. The individual private data is tied with clients by examining the correspondence deals recognizable all around, which fills in as an enlargement between social affiliations and correspondence systems. Character preliminary unmistakable confirmation in context of DNS is shown in [7]. It uncovers a district security encroach of helpful clients when the client passes on unique DNS empowers with her adaptable IPs including geo-territory data. The framework needs the misfortune's DNS have name to play out a solid checking to profile focused on clients' zone arrangement, starting now and into the foreseeable future does not related with voyagers' district revelation.

Protection spillage in conventional online informal communities (OSN) has been broadly concentrated, for example, [6]. These writing for the most part concentrate on the protection issues in informal communities in view of the client distributed information, for example, distinguishing client relationship furthermore, describing client designs. After the commonness of substance conveyance systems $(\mathrm{CDN})$ and promotion systems, reidentification in outsider aggregators turns into another security concern. It is conceivable to total protection data sent from various sites and describe the linkable property to profile particular clients on the outsider servers [2] [3]. To conquer this issue, different protection control instrument for outsider aggregators are considered [4] [6].

\section{USER PRIVACY}

An "insurance warm" system should be protected from three specific layers: customer circle, recipient circle and joint circle. Customer circle makes the data, recipient circle gets the data and joint circle has the data what's more, gives organizations. In individuals when all is said in done hotspots, customer circle suggests

to the specific contraptions of the voyagers/customers who get to the WiFi frameworks while in a rush. Recipient hover implies the servers or databases that get customers' requesting or certain information, for instance, a site page. Joint hover implies any outcasts that incorporate into the correspondence methodology, for instance, the framework providers that give the $\mathrm{WiFi}$ advantage in the plane terminals (or bistros) or the substance transport servers that store the site information.

All around in hotspot systems, clients are accepted to be in charge of their own specific security insistence by not getting to delicate data in this open correspondence condition. Our work centers around recognizing security spillage in the central circle and attempts to understand reasons why spillage still occurs. In spite of the client circle, our work can correspondingly be identified with the second and third float by demonstrating how more verified plot/association of the second and third circle can diminish the security spillage in the fundamental circle.

Security unit: a piece of information that fuses customer security. It is the humblest unit used to check an event of assurance spillage. Customer insurance relates to customer information, for instance, character, name, address, work, and interests. We propel groupings them into five sub-classes: identity insurance, region security, money related assurance, standardized savings and individual assurance.

Personality protection implies a man's name, SSN, driver permit number and other data that can perceive who the individual is. Domain security melds a client's zone takes after, for example, where he is, the spot he has been, and what put he as every now and again as possible goes to. Money related security is a man's budgetary propensities or condition, for example, his online exchanges, the merchandize he beginning late investigated, his stocks and other money related data. Social protection melds a client's social data, for example, relationship and closeness with his partners, relatives, assistants, or club individuals.

Solitary protection is the sort of data that can reflect a client's very close properties. For instance, where he grew up, helpful conditions, marriage status, propensities and side interests, sexual introduction, political perspectives, character and other individual data.

Establishment assurance consolidates contraption conspicuous verification, get to centers, advantage outline, activity system and other information related to the correspondence structure. Customer security and what's more establishment assurance could be released through customer exercises. In perspective of the importance of security unit and request of insurance, we examine the security presentation by social occasion the perceptible all around development straightforwardly WiFi frameworks.

\section{SECURITY LEAKAGE}

Spillage presentation: Because of the outside thought of $\mathrm{WiFi}$ structures, it is definitely not hard to tune in customers inside their correspondence interface as long as they are in a proportionate WiFi channel. The packs being sniffed can merge structure parameters, for instance, MAC address, IP address, MAC layer pennants, IP layer standards, show names, custom fields and the substance information in the payload if not mixed. In the wake of completing an important group examination, it is possible to consider what number of customer security units can be spilled from various structure parameters[26],[28],[30]. With a particular outrageous objective to do this, we arrange different sorts of structure works out, for instance, turning on the WiFi interface, getting 
to the Internet and surfing uncommon locale. By then we take a gander at each parameter on different structure layers and summary those that can be used to begin customers' information.

Wellsprings of spillage: despite the manner in which that the security spillage is perceived at the client end, the wellspring of the private data can begin from not just the client drift, yet additionally the beneficiary circle and the joint circle. To be increasingly explicit, protection spillage can be taken after back to three sorts of sources: clients' gadgets, site content what's more, profiled ads.

Client demand in without a doubt comprehended web documents like Google or Bing reflect private data, moreover. Particularly when clients search for delicate watchwords, for example, those identified with their helpful conditions. Recollecting the genuine goal to test what number of client confirmation units can be spilled (notwithstanding how clients are just surfing a standard site without contributing delicate data), we amass normal districts' improvement from various classes and research their security units on various security orders.

We base on our examination on most likely gotten goals, for example, Google, Yahoo, Amazon and other best five districts from various zones, for instance, success, authoritative issues and shopping goals concerning their activity streams estimations given by Alexa [5]. We examine the spillage of various pieces of clients' private data. A composed structure of famous areas' spillage condition is showed up where "full substance" surmises the entire site can be uncovered by interfacing the "have", "library" and pass on ads exceptionally fitted for clients. Figure gives an occasion of the advancements sent by HTTP custom. By looking substance of the gatherings sent from the promoting specialists, it is conceivable to actuate clients' private data in light of profiled advertisements[32],[34],[36].

In this part, we center around perceiving profiled connects the best goals. Thusly, we can find the routinely got to unapproachable supporters that profile client online exercises. The framework is as indicated by the going with each time we open a typical site page, if the business on it is client revamped, we click it to make an improvement to the propelling server.

\section{RESULTS AND DISCUSSIONS}

We propose a dangerous thinking motor which organizations arrange parameters as information sources, deducts the security units spilled utilizing existing parameters and triggers protection saving activities. The thinking motor is appeared in Figure. It has following basic bits: an information database, spillage affirmation rules and a readied processor. It takes create deals as the data, and checks the structure parameters in the development. In the event that a parameter has been poor down and collected in the security spillage learning database, it will be set up with security inciting statutes and fight settling rules (if indispensable). The protection units spillage is deducted in perspective on the models[37],[39],[41]. By joining confirmation units being spilled and a client input fragmentary interest, reality of the security spillage is assessed. Right when the spillage is over a specific purpose of repression, the readied processor will tell the client by alarms and trigger a security attestation instrument of the framework.

The learning database keeps the induction associations about the tradition or site substance and security information being revealed. The individual information we get can in like manner be used to profile customer. These information may consolidate customer's contraption name, sex, age, zone and other individual information.

Precisely when joining these data with social affiliation stages, for example, Facebook, LikedIn and Twitter, it is conceivable to see a few clients and their record on the easygoing affiliation. Next, we give a case how we utilize this data to see a client. To verify client bewildering, we substitute client's private data with picture characters[38],[40].

Directly the name of the contraption proprietor s revealed. In the consequent stage, we look through the device proprietor name in standard social locales, for instance, Facebook, LinkedIn what's more, Twitter. We discover five individuals with same name indiverse country, of which two live in Netherlands agreeing to "LinkedIn". For this circumstance, we confine the contraption customer to two contenders and both of their associations are revealed.

\section{CONCLUSION}

We consider spam recognizable proof strategies in SNS (casual group organizations). For progressing distinguishing proof, we used post examination. The most basic scraps of information in a post are the names. Thusly the centralization of examination is marks and we depict asks about a spam area technique using its specific features.

Examination contained name scoring and semantic examination of names. mark scoring is a fit methodology for isolating spammers, yet when a spammer uses a well known tag to go up against the presence of a genuine customer, revelation advances toward getting to be convoluted. To alter for these inconveniences of name score, features using semantic closeness are completed. Right when semantic segment is joined with the name incorporate the exactness extended. The name scores and particular evaluation exhibits an extraordinary execution for consistent spam revelation. What's more,since the consideration is on mark examination simply, the strategies proposed have the upside of adaptability in various SNSs.

\section{REFERENCES}

[1] Kumaravel A., Rangarajan K.,Algorithm for automaton specification for exploring dynamic labyrinths,Indian Journal of Science and Technology,V-6,I-SUPPL5,PP-4554-4559,Y-2013

[2] P. Kavitha, S. Prabakaran "A Novel Hybrid Segmentation Method with Particle Swarm Optimization and Fuzzy C-Mean Based On Partitioning the Image for Detecting Lung Cancer" International Journal of Engineering and Advanced Technology (IJEAT) ISSN: 2249-8958, Volume-8 Issue-5, June 2019

[3] Kumaravel A., Meetei O.N.,An application of non-uniform cellular automata for efficient 


\section{An Exploration of Fiber-Optic Cables}

cryptography,2013 IEEE Conference on Information and Communication Technologies, ICT 2013,V-,I-,PP-1200-1205,Y-2013

[4] Kumarave A., Rangarajan K.,Routing alogrithm over semi-regular tessellations,2013 IEEE Conference on Information and Communication Technologies, ICT 2013,V-,I-,PP-1180-1184,Y-2013

[5] P. Kavitha, S. Prabakaran "Designing a Feature Vector for Statistical Texture Analysis of Brain Tumor" International Journal of Engineering and Advanced Technology (IJEAT) ISSN: 2249-8958, Volume-8 Issue-5, June 2019

[6] Dutta P., Kumaravel A.,A novel approach to trust based identification of leaders in social networks,Indian Journal of Science and Technology,V-9,I-10,PP--,Y-2016

[7] Kumaravel A., Dutta P.,Application of Pca for context selection for collaborative filtering,Middle - East Journal of Scientific Research,V-20,I-1,PP-88-93,Y-2014

[8] Kumaravel A., Rangarajan K.,Constructing an automaton for exploring dynamic labyrinths,2012 International Conference on Radar, Communication and Computing, ICRCC 2012,V-,I-,PP-161-165,Y-2012

[9] P. Kavitha, S. Prabakaran “Adaptive Bilateral Filter for Multi-Resolution in Brain Tumor Recognition" International Journal of Innovative Technology and Exploring Engineering (IJITEE) ISSN: 2278-3075, Volume-8 Issue-8 June, 2019

[10] Kumaravel A.,Comparison of two multi-classification approaches for detecting network attacks, World Applied Sciences Journal,V-27,I-11,PP-1461-1465,Y-2013

[11] Tariq J., Kumaravel A.,Construction of cellular automata over hexagonal and triangular tessellations for path planning of multi-robots,2016 IEEE International Conference on Computational Intelligence and Computing Research, ICCIC 2016,V-,I-,PP--,Y-2017

[12] Sudha M., Kumaravel A.,Analysis and measurement of wave guides using poisson method,Indonesian Journal of Electrical Engineering and Computer Science,V-8,I-2,PP-546-548,Y-2017

[13] Ayyappan G., Nalini C., Kumaravel A.,Various approaches of knowledge transfer in academic social network,International Journal of Engineering and Technology,V-,I-,PP-2791-2794,Y-2017

[14] Kaliyamurthie, K.P., Sivaraman, K., Ramesh, S. Imposing patient data privacy in wireless medical sensor networks through homomorphic cryptosystems 2016, Journal of Chemical and Pharmaceutical Sciences92.

[15] Kaliyamurthie, K.P., Balasubramanian, P.C. An approach to multi secure to historical malformed documents using integer ripple transfiguration 2016 Journal of Chemical and Pharmaceutical Sciences92.

[16] A.Sangeetha,C.Nalini,"Semantic Ranking based on keywords extractions in the web", International Journal of Engineering \& Technology, 7 (2.6) (2018) 290-292

[17] S.V.GayathiriDevi,C.Nalini,N.Kumar,"An efficient software verification using multi-layered software verification tool "International Journal of Engineering \& Technology, 7(2.21)2018 454-457

[18] C.Nalini,ShwtambariKharabe,"A Comparative Study On Different Techniques Used For Finger - Vein Authentication", International Journal Of Pure And Applied Mathematics, Volume 116 No. 82017 327-333, Issn: 1314-3395

[19] M.S. Vivekanandan and Dr. C. Rajabhushanam, "Enabling Privacy Protection and Content Assurance in Geo-Social Networks", International Journal of Innovative Research in Management, Engineering and Technology, Vol 3, Issue 4, pp. 49-55, April 2018

[20] Dr. C. Rajabhushanam, V. Karthik, and G. Vivek, "Elasticity in Cloud Computing", International Journal of Innovative Research in Management, Engineering and Technology, Vol 3, Issue 4, pp. 104-111, April 2018.

[21] K. Rangaswamy and Dr. C. Rajabhushanamc, "CCN-Based Congestion Control Mechanism In Dynamic Networks", International Journal of Innovative Research in Management, Engineering and Technology, Vol 3, Issue 4, pp. 117-119, April 2018.

[22] Kavitha, R., Nedunchelian, R., "Domain-specific Search engine optimization using healthcare ontology and a neural network backpropagation approach", 2017, Research Journal of Biotechnology, Special Issue 2:157-166

[23] Kavitha, G., Kavitha, R., "An analysis to improve throughput of high-power hubs in mobile ad hoc network" , 2016, Journal of Chemical and Pharmaceutical Sciences, Vol-9, Issue-2: 361-363

[24] Kavitha, G., Kavitha, R., "Dipping interference to supplement throughput in MANET", 2016, Journal of Chemical and Pharmaceutical Sciences, Vol-9, Issue-2: 357-360

[25] Michael, G., Chandrasekar, A.,"Leader election based malicious detection and response system in MANET using mechanism design approach", Journal of Chemical and Pharmaceutical Sciences(JCPS) Volume 9 Issue 2, April - June 2016.
[26] Michael, G., Chandrasekar, A.,"Modeling of detection of camouflaging worm using epidemic dynamic model and power spectral density", Journal of Chemical and Pharmaceutical Sciences(JCPS) Volume 9 Issue 2, April - June 2016

[27] Pothumani, S., Sriram, M., Sridhar, J., Arul Selvan, G., Secure mobile agents communication on intranet,Journal of Chemical and Pharmaceutical Sciences, volume 9, Issue 3, Pg No S32-S35, 2016

[28] Pothumani, S., Sriram, M., Sridhar, Various schemes for database encryption-a survey, Journal of Chemical and Pharmaceutical Sciences, volume 9, Issue 3, Pg NoS103-S106, 2016

[29] Pothumani, S., Sriram, M., Sridhar, A novel economic framework for cloud and grid computing, Journal of Chemical and Pharmaceutical Sciences, volume 9, Issue 3, Pg No S29-S31, 2016

[30] Priya, N., Sridhar, J., Sriram, M. "Ecommerce Transaction Security Challenges and Prevention Methods- New Approach” 2016 ,Journal of Chemical and Pharmaceutical Sciences, JCPS Volume 9 Issue 3.page no:S66-S68

[31] Priya, N.,Sridhar,J.,Sriram, M.“Vehicular cloud computing security issues and solutions" Journal of Chemical and Pharmaceutical Sciences(JCPS) Volume 9 Issue 2, April - June 2016

[32] Priya, N., Sridhar, J., Sriram, M. "Mobile large data storage security in cloud computing environment-a new approach" JCPS Volume 9 Issue 2. April - June 2016

[33] Anuradha.C, Khanna.V, "Improving network performance and security in WSN using decentralized hypothesis testing "Journal of Chemical and Pharmaceutical Sciences(JCPS) Volume 9 Issue 2, April - June 2016.

[34] Anuradha.C, Khanna.V, "A novel gsm based control for e-devices" Journal of Chemical and Pharmaceutical Sciences(JCPS) Volume 9 Issue 2, April - June 2016 .

[35] Anuradha.C, Khanna.V, "Secured privacy preserving sharing and data integration in mobile web environments " Journal of Chemical and Pharmaceutical Sciences(JCPS) Volume 9 Issue 2, April - June 2016

[36] Sundarraj, B., Kaliyamurthie, K.P. Social network analysis for decisive the ultimate classification from the ensemble to boost accuracy rates 2016 International Journal of Pharmacy and Technology

[37] Sundarraj, B., Kaliyamurthie, K.P. A content-based spam filtering approach victimisation artificial neural networks 2016 International Journal of Pharmacy and Technology83.

[38] Sundarraj, B., Kaliyamurthie, K.P. Remote sensing imaging for satellite image segmentation 2016 International Journal of Pharmacy and Technology8 3

[39] Sivaraman, K., Senthil, M. Intuitive driver proxy control using artificial intelligence 2016 International Journal of Pharmacy and Technology84.

[40] Sivaraman, K., Kaliyamurthie, K.P. Cloud computing in mobile technology 2016 Journal of Chemical and Pharmaceutical Sciences92.

[41] Sivaraman, K., Khanna, V. Implementation of an extension for browser to detect vulnerable elements on web pages and avoid click jacking 2016 Journal of Chemical and Pharmaceutical Sciences92.

\section{AUTHORS PROFILE}

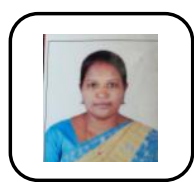

C.Geetha Assistant Professor, Department of Computer Science \& Engineering, Bharath Institute of Higher Education and Research, Chennai, India

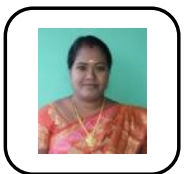

Vimala. D, Assistant Professor, Department of Computer Science \& Engineering, Bharath Institute of Higher Education and Research, Chennai, India

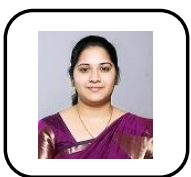

S.Amudha Assistant Professor, Department of Computer Science \& Engineering, Bharath Institute of Higher Education and Research, Chennai, India 